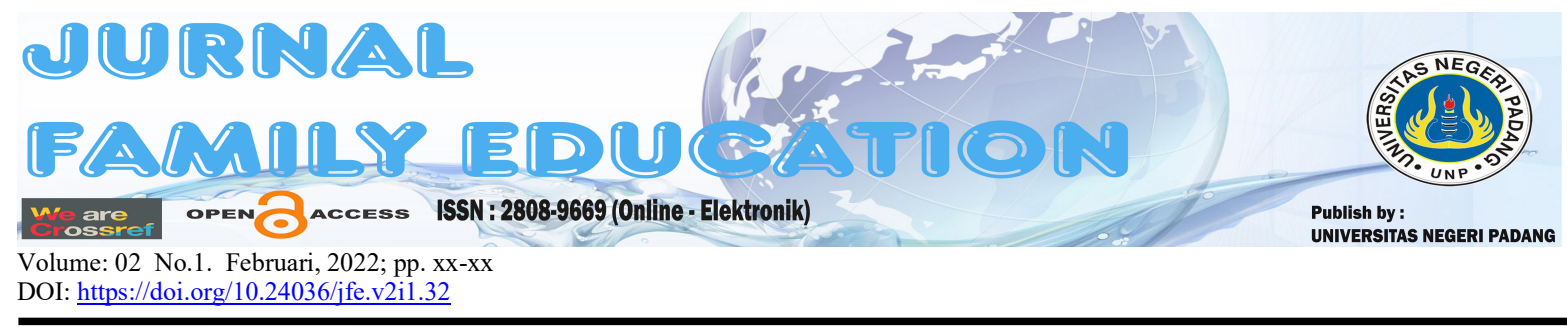

\title{
EFEKTIVITAS PENGGUNAAN KOMIK MATEMATIKA DALAM MENGENALKAN PEMBELAJARAN MATEMATIKA ANAK USIA 4-5 TAHUN DI TAMAN KANAK-KANAK
}

\author{
Ravel Darma Putra, Dadan Suryana \\ Universitas Negeri Padang \\ * e-mail: Raveldarma2000@gmail.com; suryana@fip.unp.ac.id
}

\begin{abstract}
This study aims to determine the effectiveness of the use of math comics in introducing mathematics learning to children aged 4-5 years at the Al Jannah Nanggalo Kindergarten Tarusan, South Coast District. This study linked 20 children as the research object, where 10 people entered the experimental class and 10 were the control class. The research design was a pre-test post-test control group. Collection using a scale, to test the quality of the measuring instrument used content validity test with professional judgement on the contrary to see the reliability using the help of SPSS 15.0 for windows with Alpha Crombach technique. Hypothesis testing uses the statistical technique T-test with the help of SPSS 15.0 for windows which shows a significant level of 0,000. This shows that the use of math is effective for the introduction of mathematics for children aged 4-5 years in kindergarten.
\end{abstract}

Keywords: Comics, Mathematics, Children

\section{PENDAHULUAN}

Anak usia dini merupakan anak yang terletak pada masa (golden age) yaitu pada usia 0-8 tahun, di usia ini seluruh aspek pertumbuhan dan perkembangan anak tumbuh pesat serta memiliki karakter yang berbeda pada setiap tahapan usianya. Pendidikan anak usia dini selaku usaha dalam kesiapan buat masa yang akan datang. Pendidikan anak usia dini (PAUD) dilaksanakan buat memfasilitasi pertumbuhan serta perkembangan anak secara merata. PAUD membagikan prospek kepada anak untuk memajukan karakter serta kemampuan secara optimal. Oleh sebab itu, PAUD alokasikan berbagai aktivitas yang bisa memajukan berbagai aspek perkembagan.

Suryana (2011) Anak usia dini memiliki lima aspek perkembangan, yaitu perkembangan nilai agama dan moral, kognitif, bahasa, fisik motorik, dan sosial emosional. Aspek-aspek perkembangan tersebut harus mendapatkan stimulasi optimal dari lingkungan sekitar. Stimulasi pembelajaran yang dilakukan disekolah merupakan salah satu stimulus yang dapat mengembangkan aspek-aspek tersebut diatas.

Menurut Undang-undang Nomor 20 Tahun 2003 Pasal 28 ayat 1 tentang Sistem Pendidikan Nasional mengatakan bahwa pendidikan anak usia dini dilaksanakan sebelum 
pendidikan dasar lewat jalur pendidikan formal, nonformal ataupun informal. Bagi Suryana, (2016) mengatakan anak usia dini berada pada usia dimana anak peka terhadap seluruh stimulasi yang ada pada lingkungannya, baik itu diberikan secara sengaja ataupun tidak. Di masa golden age ini terjadi kedewasan fisik serta psikis sehingga anak siap untuk menyambut serta mewujudkan semua tugas perkembangan. Usia dini ialah waktu yang paling perlu sepanjang kehidupan anak karena di saat inilah kita dapat membentuk fondasi, dasar kepribadian, membentuk potensi jasmani, rohani maupun akal serta keterampilan pada diri anak yang akan menentukan pengalaman anak dimasa yang akan datang.

Suryana (2016) mendefinisikan pendidikan anak usia dini adalah upaya pembinaan kepada anak sejak lahir hingga usia enam tahun yang dilakukan dengan memberikan rangsangan pendidikan untuk membantu pertumbuhan dan perkembangan jasmani dan rohani agar anak memiliki kesiapan untuk memasuki pendidikan lebih lanjut. Artinya dari pendapat tersebut bertujuan untuk membentuk anak yang berkualitas, yaitu anak yang tumbuh dan berkembang sesuai dengan tingkat perkembangannya sehingga memiliki kesiapan yang optimal di dalam memasuki pendidikan dasar, serta mengurangi kehidupan setelah dewasa kelak.

Pembelajaran matematika untuk anak usia dini merupakan salah satu bagian dari pendidikan. Andriyani (2016:3) mengatakan bahwa dalam kehidupan sehari-hari, ada salah satu bidang pengetahuan yang manusia gunakan yaitu matematika yang meliputi penjumlahan, pengurangan, pembagian, perkalian serta pemecahan dan masih banyak lagi. Matematika terkandung di sebagian besar kehidupan manusia. Mengandung unsur matematika seperti ketika jual beli di swalayan, hitungan hari di setiap bulan, hitungan jam, hitungan menit dan sebagainya. Pengalaman yang tepat dibutuhkan anak-anak dalam proses belajar matematika agar dapat menghargai betapa pentingnya matematika dalam kehidupan sehari-hari saat ini dan masa yang akan datang, yang merupakan salah satu pengetahuan yang digunakan dalam berbagai aktivitas.

Berdasarkan pengamatan di Taman Kanak-kanak Al Jannah Nanggalo Tarusan Kabupaten Pesisir Selatan, pengenalan matematika kepada anak yang digunakan guru yaitu gurunya kurang professional mengembangkan logika matematika anak usia 4-5 tahun, yang mana guru menjelaskan materi dan memberikan contoh tugas kepada anak. Setelah itu anak diminta untuk mengerjakan tugas-tugas di majalah atau di lembar kerja anak (LKA). Selanjutnya media yang digunakan guru hanya melalui majalah yang ada matematikanya untuk mengenalkan matematika kepada anak sehingga membuat anak kurang menarik dalam proses pembelajaran, dan terbukti bahwa guru kurang kreatif menggunakan media yang dapat menunjang pembelajaran matematika anak usia 4-5 tahun. Sehingga sedikit anak yang tidak memperhatikan penjelasan dari gurunya, dan masih ada sejumlah anak yang belum memahami konsep matematika yang diajarkan. Jadi pada penelitian ini peneliti menggunakan media baru dalam pengenalan matematika anak usia 4-5 tahun, salah satunya menggunakan komik matematika sebagai media yang akan digunakan atau diterapkan guru untuk mengenalkan matematika anak usia 4-5 tahun.

Menurut Yudhi dalam Andri Susanto (2016) komik mempunyai sifat yang sederhana dalam penyajiannya, dan memiliki unsur urutan cerita yang memuat pesan yang besar tetapi disajikan secara ringkas dan mudah dicerna, terlebih lagi komik dilengkapi dengan bahasa verbal yang dialogis. Dengan adanya perpaduan antara bahasa verbal dan non verbal ini, mempercepat pembaca paham terhadap isi pesan yang dimaksud, karena pembaca terbentuk untuk tetap fokus dan tetap dalam jalurnya.

Aspek perkembangan anak usia dini bagi Peraturan Menteri Pendidikan dan Kebudayaan Republik Indonesia No. 137 Tahun 2013 diantaranya yakni nilai agama dan moral, kognitif, fisik motorik, sosial emosional, bahasa dan seni. Salah satu aspek yang perlu ditumbuhkan pada anak dini yaitu kognitif. Menurut Suryana (2018:39) kognitif adalah proses hasil asimilasi, akomodasi, dan keseimbangan. Asimilasi berkaitan dengan proses penyerapan informasi baru kedalam 
informasi yang sudah ada dalam skema (struktur kognitif), proses akomodasi menyatukan informasi baru dengan informasi yang sudah ada dalam skema sehingga kombinasi informasi memperluas skema anak, keseimbangan berkaitan dengan upaya anak menghadapi konflik dalam dirinya ketika menghadapi suatu masalah.

Kemmapuan kognitif anak berkaitan dengan perkembangan bahasa yaitu seperti: memahami kata, mengeluarkan apa yang ia pikirkan, kemampuan logis, seperti memahami sebab akibat suatu kejadian. Piaget menyatakan bahwa perkembangan kognitif adalah proses interaksi yang berlangsung antara anak dan juga pandangan perseptual terhadap sebuah benda atau kejadian disuatu lingkungan anak. Menurut teori Jean Piaget anak-anak usia dini membangun pengetahuan mereka melalui eksplorasi aktif pada anak terhadap lingkungannya (Suryana, 2013). Perkembangan kognitif anak adalah salah satu aspek yang dapat mempengaruhi pada pertumbuhan dan perkembangan anak usia dini tersebut.

Menurut Susanto (2012) menjelaskan bahwa kemampuan kognitif pada anak usia dini berada pada masa praoperasional, artinya anak belum mampu menguasai aktivitas yang dilakukan dengan operasi mental secara logis. Pada periode ini, anak berada pada masa perkembangan "symbolic function", artinya anak mempresentasikan sesuatu dengan menggunakan kata-kata, bahasa gerak dan benda.

Salah satu media yang dapat meningkatkan pengenalan matematikan anak usia 4-5 tahun adalah komik matematika. komik matematika dikenalkan untuk mengembangkan kemampuan berhitung, konsep mengurutkan banyak sedikit benda, membaca, mengenal konsep geometri, keterampilan menyimak dan melatih kemampuan memecahkan masalah. Komik matematika merupakan salah satu media yang sangat efektif digunakan dalam mengenalkan matematika kepada anak usia dini. Meskipun pada umumnya media komik matematika masih jarang digunakan dalam mengenalkan konsep matematika kepada anak, dengan hal tersebut peneliti yakin bahwa media komik matematika juga cocok digunakan dalam pengenalan matematika kepada anak. Keefektifan komik matematika dapat dilihat dari penjelasan beberapa para ahli yang telah peneliti sampaikan, bahwa komik matematika dapat meningkatkan kemampuan matematika anak.

\section{METODE}

Bersumber pada permasalahan yang diteliti, maka jenis penelitian yang digunakan ialah kuantitatif dengan metode eksperimen dalam bentuk quashi experiment (eksperimen semu). Penelitian ini dilaksanakan di Taman Kanak-Kanak Al Jannah Nanggalo Tarusan. Pada bulan Januari 2022.

Sampel pada penelitian ini adalah kelompok A1 dan A2. Dimana kelompok A2 dijadikan kelas kontrol dengan jumlah anak 10 orang dan kelompok A1 dijadikan kelas eksperimen jumlah anak 10 orang dengan pertimbangan keadaan homogenitas yaitu uisa anak yang sama, tingkat kemampuan anak yang sama, fasilitas belajar yang sama, latar belakang kemampuan guru yang sama, dan rekomendasi dari guru kedua kelompok serta kepala sekolah Taman Kanak-Kanak Al Jannah Nanggalo Tarusan.

Untuk mengukur tingkat perkembangan matematika anak usia 4-5 tahun, peneliti menggunakan instrumen penilaian, pada instrumen penilaian terdapat indikator-indikator yang akan dicapai oleh anak. Dimana diberi skor pada setiap indikator yang telah ditentukan dengan mempertimbangkan terhadap perkembangan matematika anak.

\section{HASIL DAN PEMBAHASAN}

\section{Jurnal Family Education}

Open Access Journal 
Analisis perbandingan buat mengenali distribusi data, hingga dicoba pengujian normalitas guna mengenali data yang diolah apakah data yang berdistribusi normal, pengujian memakai uji Liliefors, agar didapatkan informasi mengenai suatu informasi berdistribusi normal ataupun tidak.

\section{Tabel 1. Uji Normalitas Liliefors}

\section{Significance Correction}

\begin{tabular}{|l|r|r|r|r|r|r|}
\hline \multirow{2}{*}{ Kelas } & \multicolumn{2}{|c|}{$\begin{array}{c}\text { Kolmogorov- } \\
\text { Smirnov(a) }\end{array}$} & \multicolumn{3}{c|}{ Shapiro-Wilk } \\
\cline { 2 - 7 } & $\begin{array}{c}\text { Statist } \\
\text { ic }\end{array}$ & Df & \multicolumn{1}{c|}{ Sig. } & \multicolumn{1}{c|}{$\begin{array}{c}\text { Statist } \\
\text { ic }\end{array}$} & df & \multicolumn{1}{c|}{ Sig. } \\
\hline $\begin{array}{l}\text { Kelas } \\
\text { Eksperi } \\
\text { men }\end{array}$ &, 155 & 10 &, $200(*)$ &, 939 & 10 &, 547 \\
$\begin{array}{l}\text { Kelas } \\
\text { Kontrol }\end{array}$ &, 190 & 9 &, $200(*)$ &, 878 & 9 &, 150 \\
\hline
\end{tabular}

Bersumber pada tabel didapatkan nilai Sig Kolmogorof-Smirnov dari kelas eksperimen yakni 0,200 serta kelas kontrol yakni 0,200. Setelah perhitungan tersebut, disimpulkan bahwasannya rata-rata data berdistribusi normal disebabkan memiliki lebih dari alpha 0,05 . Hasil dari kelas eksperimen memiliki sig sebanyak 0,200 serta kelas kontrol memiliki sig sebanyak 0,200. Dengan demikian didapatkan kesimpulan bahwa data yang diperoleh berdistribusi normal.

Setelah itu, dilakukan uji homogenitas untuk melihat apakah data bersifat homogeny ataupun tidak. Uji homogenitas varians, apabila $\mathrm{F}$ hitung lebih besar dibanding $\mathrm{F}$ table ( $\mathrm{Fh}>\mathrm{Ft}$ ) sesuai dengan taraf signifikansi $\mathrm{a}=0,05$ kedua data kelompok berasal dari varians yang homogeny ataupun data bersifat homogen bila nilai sig $>0,05$.

\section{Tabel 2. Uji Homogenitas}

\section{Test of Homogenity of Variances}

Hasil Belajar

\begin{tabular}{|c|c|c|c|}
\hline $\begin{array}{c}\text { Levene } \\
\text { Statistic }\end{array}$ & df1 & df 2 & Sig. \\
\hline $\mathbf{1 , 3 0 7}$ & 3 & 36 & ,287 \\
\hline
\end{tabular}

Bersumber pada tabel diatas, dapat diperoleh kesimpulan bahwasannya nilai signifikannya yakni 0,287 disebabkan nilai signifikannya lebih dari pada 0,05 ialah $0,287>0,05$ sehingga dikatakan data homogen. Dikarenakan kelas ini homogeny maka penelitian dapat dilakukan.

Selanjutnya dilakukan analisis data. Uji memakai t-tes dengan uji independent sample ttest ialah uji dengan membandingkan rata-rata dari 2 kelompok sampel. Sebelumnya dilakukan uji hipotesis sebelum uji independent sample t-test, maka dicari $\mathrm{N}$ gain score pada tiap-tiap kelas sampel. Setelah itu pada hasil tabel ataupun output SPSS yang dihasilkan bisa dilihat nilai Sig-2 tailed buat mengetahui apakah terdapatnya perbedaan yang signifikan.

\section{Tabel 3. Independent Sample Test}




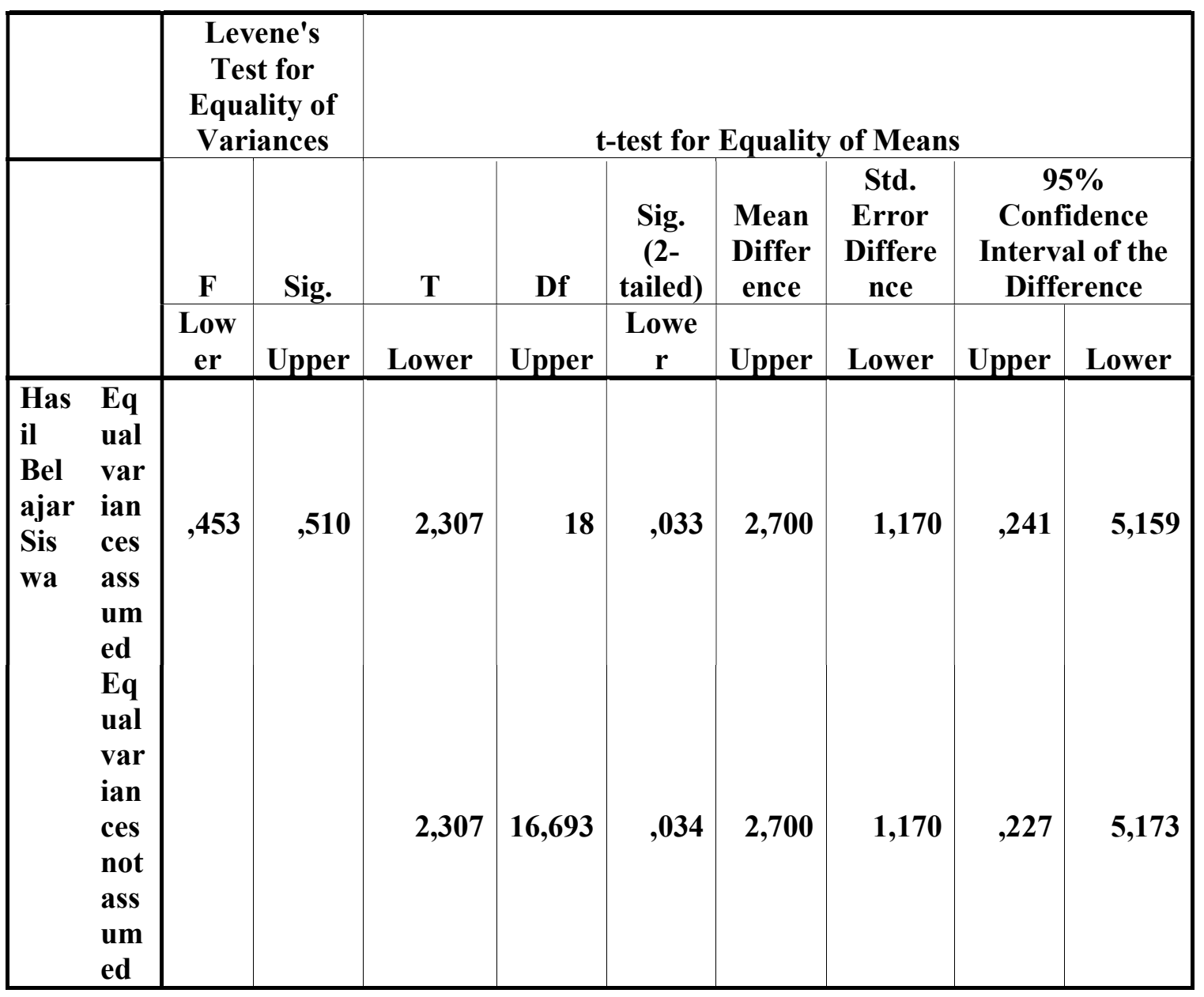

Bersumber pada hasil uji t-test diperoleh hasil dengan $\mathrm{t}=2,307$, dengan taraf signifikannya 0,033. Peihal ini memperlihatkan adanya perbedaan kemampuan matematika anak di kelas eksperimen serta kelas kontrol. Sebaliknya buat mengenali seberapa efisien komik matematika digunakan effect size dengan teknik cohen's $d$. Cohen's $d$ ialah teknik yang mengukur perbandingan antara mean buat tingkatan variabel independen dipecah dengan deviasi standar pada kelompok. Bersumber pada rumus cohen's tersebut didapatkan nilai effect size sebesar 1,03 sehingga penggunaan komik matematika efektif untuk pengenalan matematika anak usia 4-5 tahun di Taman Kanak-Kanak Al Jannah Nanggalo Tarusan.

\section{KESIMPULAN}

Dari hasil analisis data, dapat disimpulkan: 1) Data berdistribusi normal dan homogen. 2) Uji efektifitas dengan uji-t memperlihatkan perbandingan kelas eksperimen dengan kelas kontrol, bersumber pada nilai signifikansi dengan uji effect size 1,03 yang berarti kalau komik matematika efektif terhadap pengenalan matematika anak usia 4-5 tahun. 


\section{DAFTAR RUJUKAN}

Andriyani, Lisa. (2016). Strategi Pembelajaran Matematika Realistik dalam Mengenalkan Matematika Permulaan pada Anak Kelompok A di TK Ananda Kudus. Skripsi: Universitas Negeri Semarang

Arikunto, Suharsimi. (2016). Manajemen Penelitian. Jakarta: PT Rineka Cipta

Ariyanti, Tatik. (2016). Pentingnya Pendidikan Anak Usia Dini Bagi Tumbuh Kembang Anak. Jurnal Dinamika Pendidikan Dasar (Volume 8 No 1, Maret 2016), 50-58

Hulu, Taruli. (2019). Analisis Data Statistik Parametrik Aplikasi SPSS dan STATCAL: Yasasan Kita Menulis.

Indrijati. (2016). Psikologi Perkembangan dan Pendidikan Anak Usia Dini. Jakarta: Kencana.

Kementerian Pendidikan dan Kebudayaan. (2015). Pedoman Penilaian Hasil Pembelajaran Kurikulum 2013. Jakarta: Direktorat Jenderal Pendidikan Anak Usia Dini dan Pendidikan Masyarakat.

Mansur. (2014). Pendidikan Anak Usia Dini dalam Islam. Yogyakarta: Pustaka Belajar Offset.

Mursid. (2015). Belajar dan Pembelajaran PAUD. Bandung: PT Remaja Rosdakarya

Suryana, Dadan. (2011). Efektivitas Outbound dalam Mengembangkan Kepercayaan Diri Pada Anak Taman Kanak-Kanak.

Suryana, Dadan. (2013). Pendidikan Anak Usia Dini (Teori dan Praktik Pembelajaran). Padang: UNP Press

Suryana, Dadan. (2016). Pendidikan Anak Usia Dini Simulasi dan Aspek Perkembangan Anak. Jakarta: Kencana, (2016). Stimulasi dan Aspek Perkembangan Anak. Jakarta: Kencana Prenada Media Group

Suryana, Dadan. (2018). Stimulasi \& Aspek Perkembangan Anak. Jakarta: PRENADAMEDIA GROUP

Susanto, E. (2012). Model Pembelajaran Akuatik Siswa Prasekolah. Journal of Physical Education and Sport, 1(1), 37-47

Utoyo, Setiyo. 2017. Metode Pengembangan Matematika Anak Usia Dini. Gorontalo: Ideas Publishing 